\title{
Las normas de disciplina social en las sociedades cooperativas
}

\author{
Enrique Gadea \\ Universidad de Deusto \\ Fernando Sacristán \\ Universidad Rey Juan Carlos
}

Sumario: I. Introducción. II. Las faltas sociales. III. Las sanciones sociales. IV. El procedimiento sancionador. V. La expulsión.

Resumen: El objeto de este trabajo es analizar los tipos de faltas en que pueden incurrir los socios de una cooperativa, así como las sanciones que les pueden ser aplicadas y los trámites del procedimiento sancionador, con indicación de los posibles recursos. También se aborda el tema de la expulsión. Es cierto que constituye la sanción más grave, pero ello, a nuestro juicio, no justifica que las distintas normas contengan una regulación diferenciada a las restantes, con tramitación específica y recursos y plazos propios.

Palabras clave: Faltas; sanciones y procedimiento sancionador en las cooperativas.

Abstract: The purpose of this study is to analyse the types of offences that cooperative members may be held responsible for, the sanctions that may be imposed and the disciplinary procedures, pointing out the possible appeals. Expulsion of coop members is also examined. While this is certainly the most extreme measure, it cannot justify different rules imposing different conditions from the rest, with specific procedures, appeals and deadlines.

Key words: Offences; disciplinary procedures and sanctions in cooperatives. 


\section{Introducción}

En la normativa española, esta materia, cumplidas las pautas o mínimos legales, queda confiada a la capacidad autorreguladora de cada cooperativa. En efecto, en las distintas leyes se incluye como mención obligatoria de los estatutos la referencia a las normas de disciplina social, que deben determinar con precisión los tipos de faltas en que pueden incurrir los socios, su graduación y prescripción, así como las sanciones que les sean aplicables y los trámites del procedimiento sancionador, con indicación de los posibles recursos [así, por todos, art. 11, letra m) LCoop].

Aspecto esencial es que estas normas sean redactadas de forma clara y precisa. La inclusión de fórmulas indeterminadas, ambiguas o abiertas favorecedoras de la discrecionalidad rectora generarán litigiosidad entre los socios y la sociedad, con el consiguiente perjuicio para el buen funcionamiento de la cooperativa. $Y$, como sostiene la jurisprudencia, que sean objeto de interpretación restrictiva, dado que debe rechazarse toda interpretación extensiva del derecho sancionador y de las normas limitativas de derechos, debiendo resolverse las dudas en sentido favorable al socio afectado ${ }^{1}$ y debe regir siempre el principio de proporcionalidad, existiendo varias sentencias que declaran la nulidad del acuerdo de expulsión porque la conducta realizada por el socio no tenía apoyo concreto en un precepto estatutario².

\section{Las faltas sociales}

\subsection{La previa tipificación estatutaria de las faltas sociales y su clasificación}

Los socios sólo podrán ser sancionados por las faltas previamente tipificadas. La LCoOp vigente (art. 18.1) suprime la opción, que admitía la anterior (art. 37.1), de que las faltas leves pudieran ser tipificadas en el RRI o por acuerdo de la AG, por lo que, en todo caso, su regulación debe recogerse en los estatutos, aunque se mantiene esa posibilidad en otras leyes ${ }^{3}$.

1 STS de 28 de diciembre de 2000.

2 STS de 2 de marzo de 1999, SAP Alicante de 12 de noviembre de 2002, etc.. No obstante, a favor de la validez del RRI para tipificar causas de una baja obligatoria, a pesar de no estar contemplada en los estatutos, se pronuncia la STS de 1 de junio de 2004.

3 Art. 29.1 LCPV, art. 19.1 LCCAT y art. 25.1 LCG. 
Especial consideración merece el caso de las CTA, en las que las transgresiones disciplinarias que pueden cometer los socios se dividen en dos tipos de faltas:

a) Faltas sociales (las aplicables a toda cooperativa), que son las acciones $u$ omisiones relacionadas con el orden institucional de la sociedad.

b) Faltas laborales (las especificas por razón de la clase de cooperativa), que son las acciones $u$ omisiones derivadas o relacionadas con la prestación de trabajo.

Lo destacable es que el régimen disciplinario de los socios trabajadores puede figurar en los estatutos o en el RRI (art. 82.1 LCoop) o incluso en algunas leyes ser establecido por la AG (art. 102 LCPV). Según la LCoOp los procedimientos sancionadores con expresión de los trámites, recursos y plazos, deben figurar siempre en los estatutos, mientras que el resto del régimen disciplinario puede figurar en el reglamento referido: tipos de faltas que puedan producirse en la prestación de trabajo, las sanciones, los órganos y personas con facultades sancionadoras delegadas (art. 82.1).

Los estatutos clasificarán las faltas en leves, graves y muy graves. La mayoría de las leyes conceden amplía libertad para incluir las faltas dentro de una u otra categoría, aunque, en este punto, cabe destacar que alguna Ley autonómica limita el catálogo de faltas graves.

Concretamente, el artículo 23.2 LCCV señala que: «sólo podrán ser consideradas faltas muy graves las siguientes:

a) La realización de actividades o manifestaciones que puedan perjudicar los intereses de la cooperativa, como operaciones en competencia con ella, salvo lo dispuesto en el artículo 27, letra e) de esta Ley; o el fraude en las aportaciones $u$ otras prestaciones debidas a la cooperativa.

b) El incumplimiento del deber de participar en la actividad económica de la cooperativa, de acuerdo con los módulos fijados en los estatutos sociales y, en su caso, en el reglamento de régimen interior.

c) El incumplimiento de la obligación de desembolsar las aportaciones a capital social.

d) El incumplimiento persistente o reiterado de las obligaciones económicas, asumidas frente a la cooperativa.

e) Prevalerse de la condición de socio de la cooperativa para realizar actividades especulativas o ilícitas». 
Ante la parquedad de nuestras leyes, parece conveniente ofrecer al lector una orientación de las faltas que suelen incluir los estatutos en cada categoría, atendiendo a su importancia, trascendencia y consecuencias económicas y/o sociales.

Entre las faltas leves, se suelen incluir:

- No observar las normas establecidas para el buen orden y desarrollo de la cooperativa.

- Incumplir, una vez al menos, los preceptos estatutarios, reglamentarios y normas de funcionamiento por ignorancia inexcusable.

- No asistir sin causa justificada a los actos sociales, y particularmente a las asambleas generales, a que fuesen convocados.

Entre las faltas graves, cabe destacar:

- La reincidencia en faltas leves, en un período inferior a un año.

- No aceptar o dimitir, sin causa justificada a juicio del CR o no servir diligentemente los cargos sociales para los que fueren elegidos.

- El retraso en el cumplimiento de las obligaciones económicas previstas en los estatutos.

$Y$, finalmente, entre las faltas muy graves, cabe mencionar:

- La reincidencia en las faltas graves en un período inferior a un año.

- Incumplir de forma notoria los acuerdos válidamente adoptados por los órganos competentes.

- Las acciones u omisiones que, por su naturaleza, puedan perjudicar los intereses materiales o prestigio social de la cooperativa, tales como operaciones de competencia, fraude en las aportaciones o prestaciones, manifiesta desconsideración a los administradores o representantes de la entidad ${ }^{4} \mathrm{y}$ otros similares.

- Atribuirse funciones propias del CR.

- Violar el secreto de la correspondencia o documentos reservados de la cooperativa o revelar datos de reserva obligada de la misma.

- Las falsificaciones de documentos, firmas, estampillas, marcas o datos análogos relevantes para la relación de la cooperativa con socios o terceros.

4 La STS de 16 de septiembre de 2004 decreta la nulidad del acuerdo de expulsión de un socio por expresiones desconsideradas hacia el consejo rector por falta de pruebas de que ese hecho haya causado perjuicio a los intereses y prestigio de la entidad. 
— La oposición sistemática y proselitismo públicos contra los fundamentos sociales de la cooperativa.

- El incumplimiento grave o reiterado de las obligaciones previstas en las Ley.

\subsection{La prescripción de las faltas sociales}

La regulación de la prescripción de las faltas sociales ha sido valorado positivamente por la doctrina, dado que, con la fijación de los plazos de prescripción, se introduce un factor de seguridad jurídica y se obliga al CR a resolver y notificar el acuerdo recaído en los procedimientos sancionadores en un plazo breve ${ }^{5}$

En la regulación de esta materia, deben tomarse en consideración tres cuestiones fundamentales: los plazos de prescripción, la fecha de inicio del cómputo de esos plazos y la interrupción del plazo de prescripción. Nota común a las tres es la injustificada falta de uniformidad en nuestra legislación interna.

Los plazos de prescripción quedan fijados en la LCoop, después de que hayan sido duplicados respecto a su predecesora de 1999, en dos meses para las faltas leves, cuatro para las graves y seis para las faltas muy graves en la citada ley (art. 18.2), que siguen alguna otra norma6, que se reducen a uno, dos y tres meses respectivamente en la mayoría de leyes autonómicas ${ }^{7}$ y se amplía en alguna otra ${ }^{8}$.

Tampoco existe uniformidad en la fecha de inicio del cómputo de los plazos. En este punto, la mayor divergencia deriva del nuevo criterio adoptado por la LCoOp (art. 18.2), que, a pesar de las numerosas enmiendas que pedían la modificación de este extremo para evitar la imposibilidad de sancionar faltas por desconocimiento o por ocultación de hechos u omisiones, establece que los plazos «empezarán a computarse a partir de la fecha en que se haya cometido» la falta ${ }^{9}$. Sin embargo, la mayor parte de las normas se han decantado por seguir el

5 Morillas/Feliú, Curso de Derecho de Cooperativas, Madrid, Tecnos, 2. ${ }^{a}$ ed., 2002, p. 215; y Elejabarrieta, "Comentarios a los artículos 28 y 29», en Glosa a la Ley de Cooperativas de Euskadi, Vitoria, CSEE, 1999, p. 118.

6 Art. 25.2 LCCM.

7 Art. 29.2 LCPV, art. 19.2 LCCAT, art. 28.2 LSCEX, art. 25.2 LCG.

8 Art. 23.4 LCCV, los fija en tres, seis y doce meses, en función de la clase de infracción.

9 Este criterio ha sido seguido también por el art. 24.1 LCCL y art. 23.4 LCCV, si bien con la salvedad en esta última de que los plazos de prescripción son más amplios: como ha quedado señalado, en el caso de las faltas muy graves alcanza los doce meses. 
criterio de la LGC de 1987, por lo que fijan dos reglas con las que conjugar los intereses, en principio contrapuestos, de la cooperativa y de los socios ${ }^{10}$

Como regla general, la fecha para el cómputo es la del conocimiento por los administradores y no la de la comisión de la infracción, con lo que se defiende a la cooperativa de las maniobras de ocultación del infractor para conseguir la impunidad. En ese caso, el CR deberá acreditar en el expediente la fecha en que tuvo conocimiento de la transgresión cometida por el socio y aportar los medios de prueba necesarios a tal fin.

La regla anterior aparece acompañada por otra, orientada a dar seguridad al socio y estimular a los administradores a actuar diligentemente, que establece que, en cualquier caso, el plazo de prescripción empieza a contar a los seis meses ${ }^{11}$ o a los doce meses ${ }^{12}$ de haberse de conocido la infracción por el CR.

En principio, el plazo de prescripción se interrumpe al incoarse el procedimiento sancionador, pero, en unos casos, la interrupción sólo producirá efecto si en el mismo recayese acuerdo y fuese notificado en el plazo de tres meses desde su inicio ${ }^{13}$ y en otros corre de nuevo si en un determinado plazo (cuatro meses, según el art. 18.2 LCoop y mayoría de las leyes autonómicas ${ }^{14}$, y tres, según otras ${ }^{15}$ ) no se dicta y notifica la resolución.

La expresión "corre de nuevo» utilizada por las normas reseñadas provoca dudas sobre si se trata de un supuesto de interrupción o de suspensión del plazo: en el primer caso, empezaría a contar de nuevo por entero; en el segundo, se reanudaría el cómputo en el punto en que quedó suspendido. Si transcurrido ese plazo después del inicio del expediente, no se concluye éste con la notificación de su resolución, la prescripción se reanudará donde quedó interrumpida (suspendida, en realidad, aunque la suspensión sea más propia del instituto de la caducidad que del de la prescripción) ${ }^{16}$.

10 Elejabarrieta, op. cit., p. 118.

11 Art. 19.3 LCCAT, art. 28.2 LCEX.

12 Art. 29.2 LCPV, art. 25.2 LCCM y art. 25.2 LCG.

13 Art. 28.2 LCEX y 25.2 LCG.

14 Art. 29.2 LCPV, art. 25.2 LCCM.

15 Art. 19.2 LCCAT.

16 Coincidimos con Morillas/Feliú, op. cit., p. 216, y con la SAP Las Palmas de 7 de junio de 2005) en considerar que si, transcurrido ese plazo después del inicio del expediente, no se concluye éste con la notificación de su resolución, la prescripción se reanudará donde quedó interrumpida (suspendida, en realidad, aunque la suspensión sea más propia del instituto de la caducidad que del de la prescripción). 


\section{Las sanciones sociales}

\subsection{La previa tipificación estatutaria de las sanciones y su determinación}

Al igual que en el caso de las faltas, las sanciones deben aparecer previamente tipificas en los estatutos. En este punto, sólo algunas leyes contienen una lista de posibles sanciones ${ }^{17}$; otras se limitan a regular expresamente algunas de ellas como la suspensión de derechos ${ }^{18} y$, especialmente, la expulsión ${ }^{19}$, a la que por su importancia dedicaremos un apartado especial.

Dentro de la lista de sanciones, cabe destacar la amonestación, el apercibimiento, las sanciones económicas, la suspensión de derechos sociales y la expulsión.

Tomando como referencia un modelo real de estatutos, nos referiremos a una posible lista de sanciones por cada clase de falta:

Por faltas leves:

- Amonestación por escrito.

- Suspensión del derecho a voto por un plazo de hasta un año.

- Sanción pecuniaria de hasta el 3 por cien de la cuantía de la aportación obligatoria inicial vigente en cada momento.

Por faltas graves:

- Todas las del apartado anterior.

- Apercibimiento por escrito que, a juicio del consejo rector podrá hacerse público.

- Suspensión del derecho a voto por un plazo de hasta dos años.

- Inhabilitación para ser elegido para cualquier cargo social hasta en dos siguientes elecciones consecutivas.

- Sanción pecuniaria de hasta el 6 por cien de la cuantía de la aportación obligatoria inicial vigente en cada momento.

Por faltas muy graves:

- Todas las del apartado anterior.

- Suspensión de todos o algunos de los derechos sociales por un plazo de hasta tres años.

17 Art. 29 LCPV, art. 25.1 LCCM.

18 Art. 18. 4 LCOOP; art. 21.2, letra d) LCAND.

19 Art. 18.4 LCOOP, art. 28 LCPV, art. 21 LCCAT, art. 22 LCAND, art. 23.5 LCCV, art. 27 LCEX o art. 23 LCAR. 
- Sanción pecuniaria de hasta el 10 por cien de la cuantía de la aportación obligatoria inicial vigente en cada momento.

- Expulsión.

\subsection{La sanción de suspensión de derechos sociales}

En la regulación de esta sanción se aprecian dos tendencias claramente diferenciadas: la autorreguladora y la restrictiva.

Según la primera, únicamente es necesario que el ámbito y el alcance de la suspensión de los derechos del socio venga determinado necesariamente por los estatutos sociales ${ }^{20}$. Repárese en que el modelo de estatutos reproducido en el apartado anterior sigue esta primera tendencia.

Según la segunda, la regulación de la suspensión de derechos en los estatutos se encuentra condicionada por las causas que pueden originarla y por los derechos que pueden ser objeto de suspensión (LCoOp y algunas leyes autonómicas). En cuanto a las causas, señalar que los estatutos sólo podrán prever la suspensión en los supuestos en que el socio esté al descubierto de sus obligaciones económicas o no participe en las actividades cooperativizadas, en los términos establecidos estatutariamente (art. 18.4 LCoOP y concordantes autonómicos $\left.{ }^{21}\right)$.

Ello no significa que estas infracciones del socio siempre hayan de ser sancionadas con la suspensión de derechos. Podrá ser sancionado a más; en efecto, los impagos de cierta cantidad o la falta de actividad notable o significativa pueden ser tipificados en los estatutos como faltas muy graves, y, como tales, ser castigados con la expulsión y también a menos, si la infracción no supera los umbrales previstos en los estatutos 22 .

Respecto a los derechos que no pueden ser objeto de suspensión, mencionar el derecho político de información y los derechos económicos de percibir retorno, de devengo de intereses por las aportaciones al capital social y el de actualización de las mismas (art. 18.4 LCoOp y concordantes autonómicos ${ }^{23}$ ). La imposibilidad de suspender el derecho de información ha sido criticada por la incongruencia que supone que el

20 Art. 29.4 LCPV y art. 25.4 LCCM.

21 Art. 21.2, letra d) LCAND y 25.4 LCG.

22 Morillas/Feliú, op. cit., p. 221.

23 Art. 21.2, letra d) LCAND. Además, la LCG limita también la posibilidad de suspensión al derecho de asistencia a la AG con voz (art. 25.4). 
CR venga obligado a seguir informando a socios sancionados por competencia con la cooperativa o por no guardar secreto ${ }^{24}$.

También existe divergencia a la hora de determinar la duración de la suspensión. En algunas normas, se prevé expresamente que la suspensión terminará en el momento en que el socio sancionado «normalice su situación» ${ }^{25}$. En las que no contienen referencia expresa a esta cuestión (LCOOP, LCPV o LCCM), la duración de la sanción dependerá de lo impuesto en el acuerdo sancionador, de acuerdo con la tipificación prevista en los estatutos (que, en ocasiones, sólo fijan un plazo máximo para la sanción). En defecto de referencia a la duración de la sanción en el acuerdo sancionador, se aplicará la regla del momento en que el socio normalice su situación, salvo que en los estatutos estuviese determinado con claridad un plazo concreto para la sanción o los requisitos necesarios para poder ejercer nuevamente los derechos objeto de suspensión (por ejemplo, compensaciones por los perjuicios causados).

\section{El procedimiento sancionador}

El procedimiento sancionador y los recursos que procedan deberán establecerse en los estatutos, respetando las siguientes normas:

a) Competencia. La facultad sancionadora es competencia indelegable de los administradores (art. 18.3, letra a) LCoOP y concordantes autonómicos 26 ).

Esta regla no rige, en determinadas leyes, para las faltas laborales imputables a los socios de CTA y aquéllas a las que se aplican sus normas, en las que los estatutos o el RRI pueden establecer "los órganos y personas con facultades sancionadoras delegadas» (art. 82.1 LCoop y concordantes autonómicos ${ }^{27}$ ). Existe una numerosa jurisprudencia que declara la nulidad de los acuerdos disciplinarios por infracción de esta

24 Paniagua, La sociedad cooperativa, cit., p. 187.

La STS de 28 de diciembre de 2000 se pronuncia muy expeditivamente por la nulidad de pleno derecho de los acuerdos de ratificación de la expulsión de varios socios tomados en AG, por que la sanción de suspensión de empleo y sueldo tomada previamente por el CR no podía afectar derechos políticos del socio afectado, como era el derecho a entrar y votar en $A G$.

25 Art. 21.2, letra d) LCAND; art. 25.4 LCG.

26 Art. 29.3, letra a) LCPV; art. 21.1, letra a) LCCAT; art. 21.2, letra a) LCAND; art. 25.3, letra a) LCCM, art.28.3, letra a) LCEX, art. 25.3, letra a) LCG.

27 También se contempla un sistema especial de delegación en el art. 86.2 LCAND, sobre faltas cometidas en la prestación del trabajo, en relación con las CTA. 
competencia, por ejemplo, por la imposición de la sanción por la propia $A G^{28}$.

b) Audiencia previa. En todo caso, con independencia de la gravedad de la sanción, es preceptiva la audiencia previa de los interesados [art. 18.3, letra b) LCoOp y concordantes autonómicos ${ }^{29}$ ].

Tradicionalmente, en los estatutos se contemplaba la audiencia, al menos oral, del socio afectado, aunque, en la actualidad la LCoop (art. 18.3) exige que las alegaciones se realicen por escrito en el caso de faltas graves o muy graves ${ }^{30}$. La inobservancia de este trámite determina la nulidad del acuerdo sancionatorio ${ }^{31}$, pero esto no opera si fue la propia actitud del socio la generadora de su posible indefensión 32 . Por su parte, la jurisprudencia ha señalado que en el expediente sancionador deben expresarse los hechos constitutivos de la falta y las correspondientes pruebas ${ }^{33}$.

c) Recursos. En este apartado, cabe resaltar la claridad y la precisión de la LCoOp [art. 18.1, letra c) ${ }^{34}$ ], que debería ser el modelo generalizable en el deseable proceso de uniformización legislativa. La regulación de la LCoOp se basa en las premisas siguientes:

1. ${ }^{a}$ Sin distinguir el tipo o clase de falta, se prevé que el acuerdo de sanción podrá ser impugnado en el plazo de un mes, a contar desde su notificación. Plazo que no se suspende por conciliación previa en caso de expulsión de un socio trabajador por ser ésta innecesaria ${ }^{35}$.

2. ${ }^{a}$ La impugnación se realizará ante el Comité de Recursos, si lo hubiera, que deberá resolver en el plazo de dos meses o, en su defecto, ante la AG que resolverá en la primera reunión que se celebre. Para estimular la diligencia del comité o de la AG, se establece que transcurridos los plazos sin haberse resuelto y notificado el recurso se entenderá que ha sido estimado.

28 STS de 14 de octubre de 1981, STS de 28 de octubre de 1987, STS de 28 de mayo de 1988, STS de 14 de octubre de 1993.

29 Art. 29.3., letra b) LCPV; art. 21.1, letra b) LCCAT; art. 21.2, letra C) LCAND; art. 25.3, letra b) LCCM; art.28.3, letra b) LCEX; art. 25.3, letra b) LCG.

30 La LCG prevé expresamente que el socio podrá formalizar sus alegaciones por escrito (art, 25.3), mientras que la LCAND, establece que las alegaciones deben realizarse por cualquier medio que permita su almacenamiento y acreditación, en los supuestos de faltas graves y muy graves [art. 21.2, letra c)].

31 STS de 17 de septiembre de 1987 y SAP Barcelona de 29 de enero de 1992.

32 SAP Madrid de 17 de febrero de 1997.

33 STS de 29 de noviembre de 1990.

34 En sentido similar, el art. 25.3 LCG.

35 STS Valencia de 15 de marzo de 2007. 
3. agotados los recursos societarios, algo que por Ley se impone necesariamente, si la impugnación no ha sido admitida o si ha sido desestimada, podrá recurrirse en el plazo de un mes desde su no admisión o notificación al socio ante el Juez de Primera Instancia del domicilio social (Juez de lo Mercantil) por los trámites de impugnación de acuerdos de la AG y también cabe recurrir a la vía arbitral (disp. adicional 10. ${ }^{2}$ LCoop).

Cabe señalar que en este punto hay ciertas discrepancias en los plazos previstos entre las distintas leyes cooperativas para impugnar judicialmente los acuerdos de expulsión de socios. Algunas leyes, siguen el criterio de la LCoop y establece el plazo de un mes desde su notificación al socios ${ }^{36}$; otras leyes extiende dicho plazo a dos meses ${ }^{37}$; y otras remiten, en cuanto a los plazos, al régimen general de impugnación de acuerdos ${ }^{38}$.

Este régimen especial para los casos de expulsión se aplica con preferencia y exclusión del régimen general de impugnación de los acuerdos de la AG (art. 56) o del CR (art. 62) y las previsiones sobre ejecutividad que se contienen en otros preceptos (art. 28.5) ${ }^{39}$ No son, pues, computables los plazos del artículo 18 LCoOp mediante el cómputo señalado en estos artículos, que toma como inicio un hecho distinto de la notificación, ni es necesario el voto en contra del cooperativista afectado 40 .

No obstante, si el acuerdo es considerado nulo, por ejemplo por basarse la expulsión en una causa no tipificada en los estatutos, debería operar el plazo de un año para poder impugnar el acuerdo de la AG (art. 31.3 LCOOP), y no el específico de un mes (o dos en otra leyes) previsto para recurrir judicialmente la expulsión de socios ${ }^{41}$.

El cómputo de los plazos para acudir a la vía judicial comienza el día siguiente al que se le notifica el acuerdo de no admisión o desestimiento por el Comité de Recursos o la AG y se interrumpe con la presentación de demanda judicial. No basta con la mera presencia del socio en la AG que tomo el acuerdo para considerar que ahí empieza el dies a quo, sino que se exige la notificación de forma fehaciente ${ }^{42}$.

36 Art. 21.1, letra d) LCCAT.

37 Art. 28.4 LCCV, art. 22.2 LCCM, art. 27.4 LCEX, art. 23.2, 2. ${ }^{\circ}$ LCAR.

38 Art. 26.2, $2{ }^{\circ}$ LCG que remite al art. 40: un mes los anulables y un año los nulos; art. 24.3 in fine $L C C L$, que remite al art. 39: cuarenta días los anulable y un año los nulos.

39 STS de 19 de noviembre de 2007.

40 STS de 5 de marzo de 1994.

41 SAP Salamanca de 10 de junio de 2004, Sentencia del Juzgado de Primera Instancia núm. 7 de Almería de 7 de abril de 2007

42 STS de 19 de noviembre de 2007. No ocurre así en el art. 23.2, 2. ${ }^{\circ}$ LCAR que prevé expresamente la posible comunicación del acuerdo al socio en la misma AG. 
A diferencia de lo previsto en la LCoOp, algunas leyes autonómicas $^{43}$, siguiendo lo dispuesto en la LGC de 1987, contemplan únicamente un sistema de recursos para los supuestos de sanciones por faltas graves o muy graves. Bajo la vigencia de la LGC, se planteó la duda de si era posible plantear recurso contra las sanciones por infracciones leves. En la actualidad, la doctrina coincide en que si cabe recurso, si bien la regulación estatutaria para este punto puede ser distinta de la regulación prevista en la Ley para el recurso contra las sanciones para las faltas graves y muy graves ${ }^{44}$.

\section{La expulsión}

La expulsión, o exclusión como la denominan algunas leyes cooperativas, es una de las posibles sanciones que pueden imponer los administradores a los socios por la comisión de infracciones. Es cierto que constituye la sanción más grave, pero ello, a nuestro juicio, no justifica que las distintas normas contengan una regulación diferenciada a las restantes, con tramitación específica y recursos y plazos propios.

Como en cualquier otro, en el ámbito cooperativo, pese a la libertad estatutaria existente, como complemento a los límites de la autonomía privada, procede la aplicación de los principios básicos que inspiran todo procedimiento sancionador, cuales son los de legalidad, irretroactividad, proporcionalidad entre la conducta y la sanción, equivalencia entre la conducta y la determinación del tipo de infracción, presunción de inocencia y derecho de defensa. Esos principios básicos se deben aplicar en todo caso; por tanto, lo procedente es fijar las pautas para que se regule un procedimiento sancionador general con todas las garantías, aplicable a todo tipo de sanciones, como realiza la LCOOP (art. 18).

Es difícil de justificar, no sólo desde el punto de vista sustantivo sino también sistemático, que, en algunas leyes, la expulsión (un tipo de sanción) aparezca regulada en artículo independiente, con carácter previo al régimen general de disciplina social ${ }^{45}$.

En efecto, la LCoOp, después de establecer las normas para que sea regulado un procedimiento sancionador y un sistema de recursos común a todas las sanciones, determina, en el último apartado del precepto relativo a las normas de disciplina social (art. 18.5), las es-

\footnotetext{
43 Art. 29.3, letra C) LCPV; art. 28.3, letra C) LCEX.

44 Por todos, Paz Canalejo, op. cit., p. 214.

45 Art. 28 LCPV, art. 27 LCEX, art. 23 LCAR.
} 
pecialidades (previstas también en otras leyes ${ }^{46}$ ) que el legislador ha considerado necesarias en una medida tan radical y trascendente, que son las siguientes:

1. ${ }^{a}$ La expulsión de los socios sólo procederá por falta muy grave.

La previsión es en sí correcta, aunque el tenor del precepto ha sido criticado por escueto. Se ha señalado que la lista de faltas muy graves puede ser tipificada libremente en los estatutos y, por tanto, el derecho del socio a permanecer en la cooperativa puede quedar poco protegido ${ }^{47}$. No obstante, debe quedar también anotado que la libertad no es absoluta: en todo caso, los estatutos deberán respetar los principios de proporcionalidad y de equivalencia ${ }^{48}$.

Por el contrario, se establece un catálogo de posibles faltas muy graves en el artículo 23.2 LCCV. En algunas leyes se considera sancionable con la expulsión el encontrarse el socio al descubierto de sus obligaciones económicas ${ }^{49}$.

2. ${ }^{\text {a }}$ Si la expulsión afectase a un cargo social, el mismo acuerdo podrá incluir la propuesta de cese simultáneo en el desempeño de dicho cargo.

Esta norma es introducida por la enmienda n. ${ }^{\circ} 40$ del GP Mixto en el Senado y constituye una excepción a la regla general prevista en el artículo 35, que atribuye la competencia de elección y cese de los administradores a la asamblea general ${ }^{50}$

3. ${ }^{a}$ El acuerdo de expulsión será ejecutivo una vez sea notificada la ratificación del Comité de Recursos o, en su defecto, de la AG (que lo habrá adoptado mediante votación secreta), o cuando haya transcurrido el plazo para recurrir ante los mismos sin haberlo hecho ${ }^{51}$. No obstante, previamente, el CR puede haber aplicado el régimen de suspensión cautelar previsto en el artículo 18.4 LCoop. Los efectos de la suspensión se determinarán en los estatutos, aunque el socio conservará en todo caso el derecho de voto en la AG mientras el acuerdo no sea ejecutivo (art. 17.5 LCoOp y concordantes autonómicos ${ }^{52}$ ).

46 Art. 28.1 LCPV, art. 27 LCEX, art. 26.1 LCG, art. 23 LCAR.

47 Vicent Chuliá, op. cit., p. 3, respecto a la LGC de 1987, que contenía una previsión similar.

48 Entran a valorar la intensidad de la falta muy grave tipificada en los estatutos, la STS de 31 de enero de 1992, STS de 7 de febrero de 2002, SAP Cádiz 18 de marzo de 2003, y SAP Vizcaya de 23 de septiembre de 2005.

49 Art. 27.1 LCEX y art. 26.1 LCG. De interés, al respecto, STS de 27 de enero de 1984.

50 Sobre la posible aplicabilidad supletoria de esta previsión a la LCPV y al resto de leyes autonómicas sin referencia explicita a la cuestión, Elejabarrieta, op. cit., pp. 115-116.

51 Sobre la impugnación del procedimiento de expulsión de un socio por ausencia de notificación se pronuncia la STS de 19 de noviembre de 2007.

52 Art. 27.3 LCPV y art. 21.3 LCCM. 
Con la expresión: «el acuerdo de expulsión será ejecutivo...» se pretende determinar cuándo surte efectos. Ello significa que el día de la notificación del acuerdo ratificador $\mathrm{o}$, si no se hubiese recurrido, el día siguiente al último del plazo para recurrir se producirá la baja efectiva del socio expulsado y comenzará el dies a quo para calcular el período de reembolso de sus aportaciones.

Mención particular merece el régimen previsto para la expulsión de los socios trabajadores por faltas laborales. En este punto, la LCoop reduce la libertad estatutaria que concede para determinar el régimen disciplinario de los socios trabajadores y establece una regulación especial. La norma prevé que la expulsión de los socios trabajadores sólo podrá ser acordada por el CR (a diferencia de las otras sanciones que pueden ser impuestas por "los órganos y personas con facultades sancionadoras delegadas» - art. 82.1), contra cuya decisión se podrá recurrir, en el plazo de quince días desde la notificación de la misma, ante el comité de recursos que resolverá en el plazo de dos meses o ante la asamblea que resolverá en la primera reunión que se convoque. Transcurrido dicho plazo sin haber adoptado la decisión, se entenderá estimado el recurso. El acuerdo de expulsión sólo será ejecutivo desde que sea ratificado por el correspondiente órgano o haya transcurrido el plazo para recurrir ante el mismo, aunque el CR podrá suspender al socio trabajador en su empleo, conservando éste todos sus derechos económicos (art. 82.3).

Aunque pueda parecer sorprendente uno de los comportamientos de los socios de cooperativas que han producido mayor litigiosidad judicial en materia de disciplina social ha sido el contenido en la típica cláusula estatutaria de falta grave por «la manifiesta desconsideración de los rectores y representantes de la cooperativa que atente contra los intereses o el prestigio de la entidad» ${ }^{53}$ ). El TS ha reconocido en varias sentencias la nulidad y ineficacia de acuerdos de expulsión de socios alegando esta causa sino va acompañada de un perjuicio de los intereses materiales (reducción de ventas o de servicios prestados) o el prestigio de la sociedad 54 , y que una actitud crítica, incluso con excesos verbales en el seno de la AG, no son de entidad suficiente para justificar la expulsión de un socio ${ }^{55}$.

53 SAP Sevilla de 2 de diciembre de 2004, SAP Albacete de 14 de noviembre de 2002, entre otras.

54 STS de 14 de julio de 1987 y STS de 29 de noviembre de 1990.

55 STS de 31 de enero de 1992 y STS de 7 de febrero de 2002. 